\title{
Glucosylation of Salicylic Acid in Nicotiana tabacum Cv. Xanthi-nc
}

\author{
Hyung-il Lee and Ilya Raskin
}

Biotech Center, Rutgers University, Foran Hall, Cook College, 59 Dudley Road, New Brunswick, NJ 08901-8520. Accepted for publication 10 April 1998.

\begin{abstract}
Lee, H., and Raskin, I. 1998. Glucosylation of salicylic acid in Nicotiana tabacum cv. Xanthi-nc. Phytopathology 88:692-697.

Salicylic acid (SA) is a key regulatory component of disease resistance in plants. In tobacco mosaic virus (TMV)-inoculated tobacco (Nicotiana tabacum cv. Xanthi-nc NN genotype), newly synthesized SA is converted primarily to SA 2-O- $\beta$-D-glucoside (SAG) and glucosyl salicylate (GS), a relatively minor metabolite. Similar patterns in the formation of GS and SAG were observed in tobacco inoculated with Pseudomonas syringae pv. phaseolicola, suggesting the accumulation of two glucosylated metabolites is a general phenomenon in tobacco plants. After SA infiltration,

GS was synthesized rapidly, reached a maximal level at $6 \mathrm{~h}$, declined, and remained relatively constant for at least $24 \mathrm{~h}$. In contrast, SAG content increased gradually after SA treatment. Our in vitro and in vivo data suggest that a high concentration of free SA triggers transient formation of GS and continuous accumulation of SAG, which is a more stable metabolite of SA. The two distinct SA glucosyltransferases catalyzed the formation of GS and SAG, respectively. The activities of these enzymes were enhanced by TMV or P. syringae pv. phaseolicola inoculation or SA treatment and were found in different fractions of gel filtration chromatography.
\end{abstract}

Salicylic acid (SA) is a natural phenolic compound present in many plants. SA is involved in thermogenic inflorescences of Arum lilies (28) as well as local and systemic resistance to pathogens, including induction of pathogenesis-related (PR) proteins in dicotyledonous plants, such as tobacco, cucumber, tomato, and Arabidopsis $(12,16,25,27)$.

Most of the endogenously synthesized SA in tobacco mosaic virus (TMV)-inoculated tobacco leaves (Nicotiana tabacum L. 'Xanthi-nc' NN genotype) is converted to glucosidase-hydrolyzable SA conjugate(s) $(15,26)$. In addition, significant amounts of SAderived volatile methyl salicylate are released from TMV-inoculated Xanthi-nc tobacco (30). In contrast to methyl salicylate, glucosylated form(s) of SA accumulate only in and around hypersensitive response (HR) lesions formed during the incompatible interaction between plants and viruses, bacteria, or fungi (15). There are no detectable levels of glucosylated conjugates measured in phloem sap or uninoculated leaves of TMV-inoculated plants $(15,26)$.

Different types of SA conjugates have been isolated from a wide range of plant species. Soybean cell cultures fed with $\left[{ }^{14} \mathrm{C}\right] \mathrm{SA}$ or benzoic acid accumulate glucose esters of SA (2). Labeled 2,5dihydroxybenzoic acid (gentisic acid) and 2,3-dihydroxybenzoic acid $(O$-pyrocatechuic acid) are found in leaves of various plants fed radioactive $S A$, cinnamic acid, or benzoic acid $(3,11,20)$. In roots of buckwheat (Fagopyrum esculentum), SA is 5-hydroxylated to 2,5-dihydroxybenzoic acid, followed by glucosylation at the hydroxyl group of the $\mathrm{C} 5$ position to form gentisic acid 5-O- $\beta$ D-glucoside (29). A SA amino acid conjugate, $N$-salicyloyl aspartic acid, has been detected in wild grapes (Vitis riparia and $V$. rupestris) and French beans (4,31). SA also is methylated to form a volatile ester, methyl salicylate. This SA ester has been identified in a number of plant species $(1,7-9,19)$, including wintergreen (10), in which it is the major constituent of wintergreen oil. Early studies showed that exogenously supplied $\left[{ }^{14} \mathrm{C}\right]$ benzoic acid in Helianthus annuus hypocotyls is converted to trace amounts of SA and large amounts of SA glucosides (21). Later, SA 2-O- $\beta$-D-glu-

Corresponding author: I. Raskin; E-mail address: raskin@aesop.rutgers.edu

Publication no. P-1998-0520-01R

(C) 1998 The American Phytopathological Society coside (SAG) was found in many plant species, including tobacco $(18,22,23,29,32-35)$, suggesting glucosylation is a major route of SA metabolism in a wide range of plants.

Previous studies identified SAG as the only glucosylated form in TMV-inoculated or SA-treated Xanthi-nc tobacco $(15,26)$. However, glucosyl salicylate (GS) was detected in a different tobacco cultivar (N. tabacum cv. Petit Havana SR 1) after incubation with SA (13). We identified the formation of both GS and SAG in Xanthi-nc tobacco plants inoculated with TMV or Pseudomonas syringae pv. phaseolicola. We also investigated how the synthesis of two glucosylated metabolites and their biosynthetic enzymes are regulated in tobacco.

\section{MATERIALS AND METHODS}

Plant material and pathogen inoculation. Tobacco plants $(N$. tabacum cv. Xanthi-nc NN genotype) were grown as described previously (36). The U1 strain of TMV was used to inoculate fully expanded leaves of 6- to 8 -week-old seedlings at $5 \mu \mathrm{g}$ per leaf by rubbing the leaf surface with Carborundum. After removal of main veins, whole TMV-inoculated leaves were sampled at each time point for measurement of SA content and enzyme activity.

For bacterial inoculation, an overnight culture of $P$. syringae pv. phaseolicola (NPS3121) (24) was pelleted, washed in sterile water, repelleted, and resuspended in sterile water to a final concentration of $\mathrm{OD}_{600}=0.1$. The bacterial suspension was injected into the abaxial surface of leaves with a sterile syringe. After inoculation, leaf disks immediately surrounding injected areas were collected at various time points and stored at $-20^{\circ} \mathrm{C}$ for SA quantification or at $-80^{\circ} \mathrm{C}$ for enzyme assays.

Application of SA. For SA treatment, tobacco leaves were rinsed with deionized water, and mid-veins were removed. Leaf pieces were vacuum-infiltrated with concentrations of SA ranging from 0 to $1 \mathrm{mM}$. For $\left[{ }^{14} \mathrm{C}\right]$ tracer experiments, leaf disks were infiltrated with $5 \mu \mathrm{M}\left[{ }^{14} \mathrm{C}\right] \mathrm{SA}$ of specific activity $2.1 \mathrm{Gbq} \mathrm{mmol}^{-1}$ (Sigma Chemical Co., St. Louis) and $1 \mathrm{mM}$ nonradioactive SA. After infiltration, tobacco leaf pieces and disks were kept on wet filter paper in trays covered with plastic wrap at $24^{\circ} \mathrm{C}$ under white fluorescent light $\left(200 \mu \mathrm{mol} \mathrm{m} \mathrm{m}^{-2} \mathrm{~s}^{-1}\right)$. Alternatively, leaf disks $(10 \mathrm{~mm}$ in diameter) were incubated in a solution containing $5 \mu \mathrm{M}\left[{ }^{14} \mathrm{C}\right] \mathrm{SA}$. 
The SA-treated leaves or leaf disks were harvested at the appropriate time, frozen in liquid nitrogen, and stored at $-20^{\circ} \mathrm{C}$ for SA quantification or $-80^{\circ} \mathrm{C}$ for enzyme assays.

Extraction and quantification of SA. SA was extracted and quantified as described previously $(15,28,36)$. Leaf tissue samples were ground in liquid nitrogen and extracted once in $90 \%$ methanol and then in 100\% methanol. After vacuum-drying, samples were subjected to enzymatic hydrolysis as described below or used directly for measurement of free SA. SA was quantified by highperformance liquid chromatography (Waters Corp., Milford, MA) with a spectrofluorescence detector (Waters 474) after separation on a $\mathrm{C}$ - 18 reverse-phase column equilibrated with $0.5 \%$ glacial acetic acid/methanol (3:1) at a flow rate of $1.5 \mathrm{ml} \mathrm{min}^{-1}$. All data were corrected for SA recovery, which ranged from 70 to $95 \%$.

For enzymatic hydrolysis, dried leaf samples were resuspended in $25 \mathrm{mM}$ sodium acetate buffer ( $\mathrm{pH}$ 5.0) containing 20 units of $\beta$ glucosidase (EC 3.2.1.21; almond, Sigma), which can hydrolyze both SAG and GS, or in $20 \mathrm{mM}$ Tris- $\mathrm{HCl}$ buffer ( $\mathrm{pH} \mathrm{8.0)} \mathrm{con-}$ taining 40 units of esterase (EC 3.1.1.1; porcine, Sigma), which can hydrolyze only GS. Duplicate samples incubated in the absence of enzymes were used as controls. After overnight hydrolysis, SA was extracted and quantified as described above. The levels of GS in the samples were determined by subtracting the amount of free $\mathrm{SA}$ in control samples from the SA contained in esterase-hydrolyzed samples. The levels of SAG were determined by subtracting the sum of free SA and GS from the SA present in $\beta$-glucosidasehydrolyzed samples.

Preparation of crude extract. Frozen tobacco leaves were ground in liquid nitrogen and resuspended in 1.5 volumes of $20 \mathrm{mM}$ triethanolamine (TEA) buffer ( $\mathrm{pH} \mathrm{7.3)} \mathrm{containing} 14 \mathrm{mM} \beta$-mercaptoethanol, leupeptin $\left(1 \mu \mathrm{g} \mathrm{ml}^{-1}\right), 1 \mathrm{mM}$ phenylmethylsulfonyl fluoride, $10 \%$ (wt/wt, leaf) Dowex (Sigma) 1 and 2\% (wt/vol) polyvinylpyrrolidone. The tissue slurry was filtered through Miracloth (Calbiochem-Behring Corp., La Jolla, CA), and the filtrate was cleared by centrifugation at $15,000 \times g$ for $20 \mathrm{~min}$. The supernatant was assayed for enzyme activity, and protein concentration was determined by the method of Bradford (5).

Gel filtration chromatography. Soluble proteins were prepared as described above and applied to a Superose 12 gel filtration column equilibrated with two column volumes of TEA buffer containing $14 \mathrm{mM} \beta$-mercaptoethanol and $150 \mathrm{mM} \mathrm{NaCl}$. The fractions were eluted with the same buffer at $0.5 \mathrm{ml} \mathrm{min}^{-1}$.

Enzyme assay for SA glucosyltransferases. The standard assay for two SA glucosyltransferases was performed as described by Edwards (13) with the following modifications. The reaction mixture contained an appropriate volume of the protein samples and a final concentration of $10 \mathrm{mM}$ UDP glucose (UDPG) and $200 \mu \mathrm{M}$ $\left[{ }^{14} \mathrm{C}\right] \mathrm{SA}$ of specific activity $2.1 \mathrm{Gbq} \mathrm{mmol}^{-1}$. The mixed preparations were incubated at $30^{\circ} \mathrm{C}$ for 30 to $60 \mathrm{~min}$. The reaction was stopped by adding $25 \mu \mathrm{l}$ of an ethanolic solution of $5 \mathrm{mM} \mathrm{SA}$. After placement on ice for $10 \mathrm{~min}$, samples were centrifuged for 5 min and analyzed by thin-layer chromatography (TLC) on silica gel K6F (Whatman Inc., Clifton, NJ) plates. After application of 10 to $20 \mu \mathrm{l}$ of each sample on TLC plates, the samples were developed in a solvent consisting of 1-butanol/acetic acid/water (4:1:1). Radioactive bands were visualized by autoradiography or quantified with a phosphorimager (Molecular Dynamics, Sunnyvale, CA) and IPlab Gel $\mathrm{H}$ alias program (Signal Analytics Corporation, Vienna, VA). One unit of enzyme activity converted $1 \mu \mathrm{mol}$ SA to either SAG or GS per minute.

\section{RESULTS}

Identification of GS and SAG in pathogen-inoculated tobacco. The structures of three identified metabolites of SA in Xanthi-nc tobacco are shown in Figure 1. For more precise characterization of SA conjugates in TMV-inoculated tobacco, samples were digested overnight with esterase or $\beta$-glucosidase. More than
$70 \%$ of the total SA was present in the form of $\beta$-glucosidasehydrolyzable SA glucosides (Fig. 2A), which agrees with previous studies $(14,15)$. We identified GS as a relatively minor metabolite after overnight hydrolysis of tissue samples with esterases (Fig. 2A). The levels of this glucose ester increased almost fivefold from 163.2 to $735.4 \mathrm{ng} \mathrm{g}^{-1}$ fresh weight between 2 and 4 days postinoculation. There was no detectable level of glucosylated conjugates in uninoculated tobacco (14). We also found that increases in GS and SAG were accompanied by the induction of the activities of the two enzymes (Fig. 2B): UDPG/SA carboxyl glucosyltransferase (SACGT), which catalyzes the formation of GS, and UDPG/SA 2-O-glucosyltransferase (SAGT), which converts SA to SAG. However, induction of SACGT was higher than that of SAGT, whereas the products of these enzymes accumulated in opposite ratios.

To determine whether the formation of GS is pathogen specific, tobacco leaves were inoculated with $P$. syringae pv. phaseolicola - a bean bacterial pathogen that is incompatible with tobacco (24). Large increases in free and glucosylated SA were observed at $\approx 12 \mathrm{~h}$ postinoculation, when necrotic lesions began to develop (Fig. 3A). GS increased $\approx 50$-fold, from 7 to $340 \mathrm{ng} \mathrm{g}^{-1}$ fresh weight, between 3 and $24 \mathrm{~h}$ postinoculation. At that time, 10 to $20 \%$ of total glucosylated SA was in the form of GS, while $\approx 70 \%$ of total SA was metabolized to SAG. A similar induction pattern of the two glucosyltransferases also was observed in $P$. syringae pv. phaseolicola-inoculated leaves (Fig. 3B). However, both activities increased more rapidly in the bacteria-inoculated tissues than in the virus-inoculated tissues.

Glucosylation of SA and induction of SA glucosyltransferases in SA-treated tobacco. To analyze the kinetics of SA glucosylation, tobacco leaves were infiltrated with $1 \mathrm{mM} \mathrm{SA}$, and SA metabolites were quantified by differential enzyme hydrolysis. Immediately after SA infiltration, free SA increased from 0.07 to $91.9 \mu \mathrm{g} \mathrm{g}^{-1}$ fresh weight (Fig. 4A). Thereafter, free SA continued to decrease, reaching $50 \%$ of the total SA levels between 4 and $6 \mathrm{~h}$ and $10 \%$ at $24 \mathrm{~h}$ after SA infiltration. Corresponding to the decrease

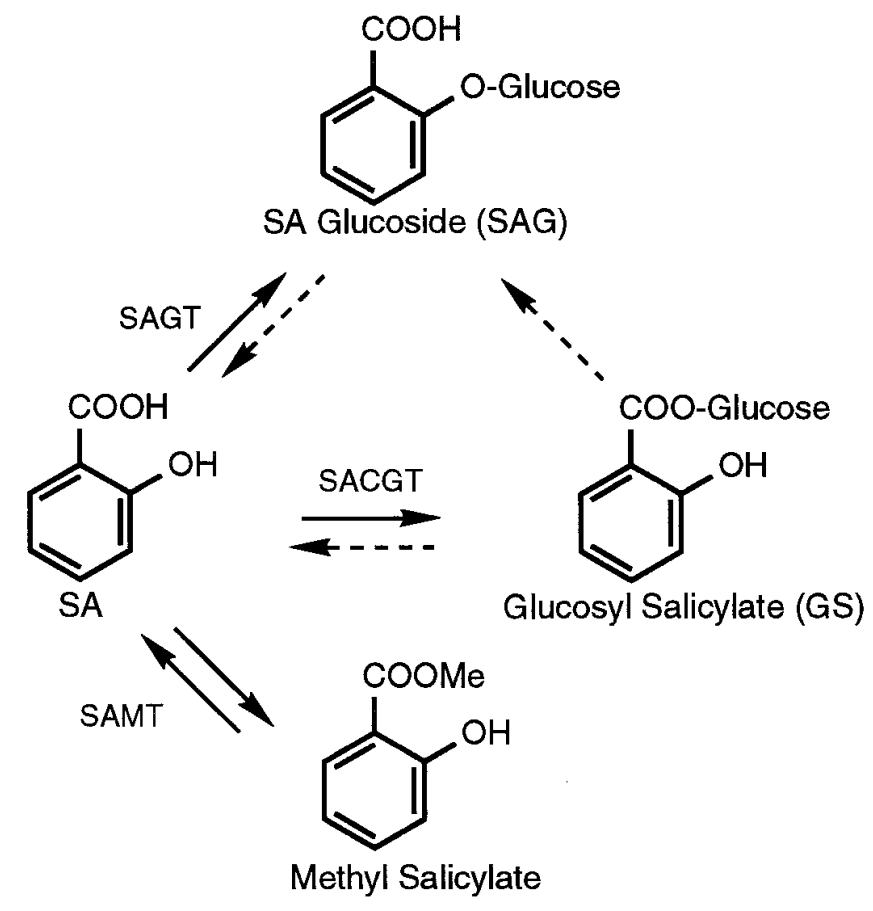

Fig. 1. Identified metabolites of salicylic acid (SA) in tobacco. Gaseous methyl salicylate is released from the site of its formation. In contrast, SA 2-O- $\beta$-Dglucoside (SAG) and glucosyl salicylate (GS) are accumulated as major metabolites. SAGT = SA 2-O-glucosyltransferase; SACGT = SA carboxyl glucosyltransferase; $\mathrm{SAMT}=\mathrm{SA}$ methyltransferase. 
in free SA, the two glucosylated forms of SA began to accumulate. GS increased rapidly and reached a maximal level of $33.8 \mu \mathrm{g} \mathrm{g}^{-1}$ fresh weight by $6 \mathrm{~h}$. Thereafter, the transiently elevated GS decreased to a relatively lower, but constant, level for the duration of the experiment. SAG levels also reached their maximum $6 \mathrm{~h}$ after infiltration but did not show any significant decrease thereafter.

The in vitro enzyme activities of the two SA glucosyltransferases also were examined in SA-infiltrated tissues. The activities of both increased in response to SA (Fig. 4B). Similar to what was seen in TMV- and $P$. syringae pv. phaseolicola-inoculated tissues, induction of SACGT by SA was three to four times higher than that of SAGT, and the relationship between product formation and enzyme activities was opposite.

Relative accumulation of GS and SAG. To determine the relative rates of synthesis and turnover in planta of the two glucosylated forms, tobacco leaf disks were infiltrated with $5 \mu \mathrm{M}\left[{ }^{14} \mathrm{C}\right] \mathrm{SA}$ and $1 \mathrm{mM}$ nonradioactive SA. After infiltration, free radioactive

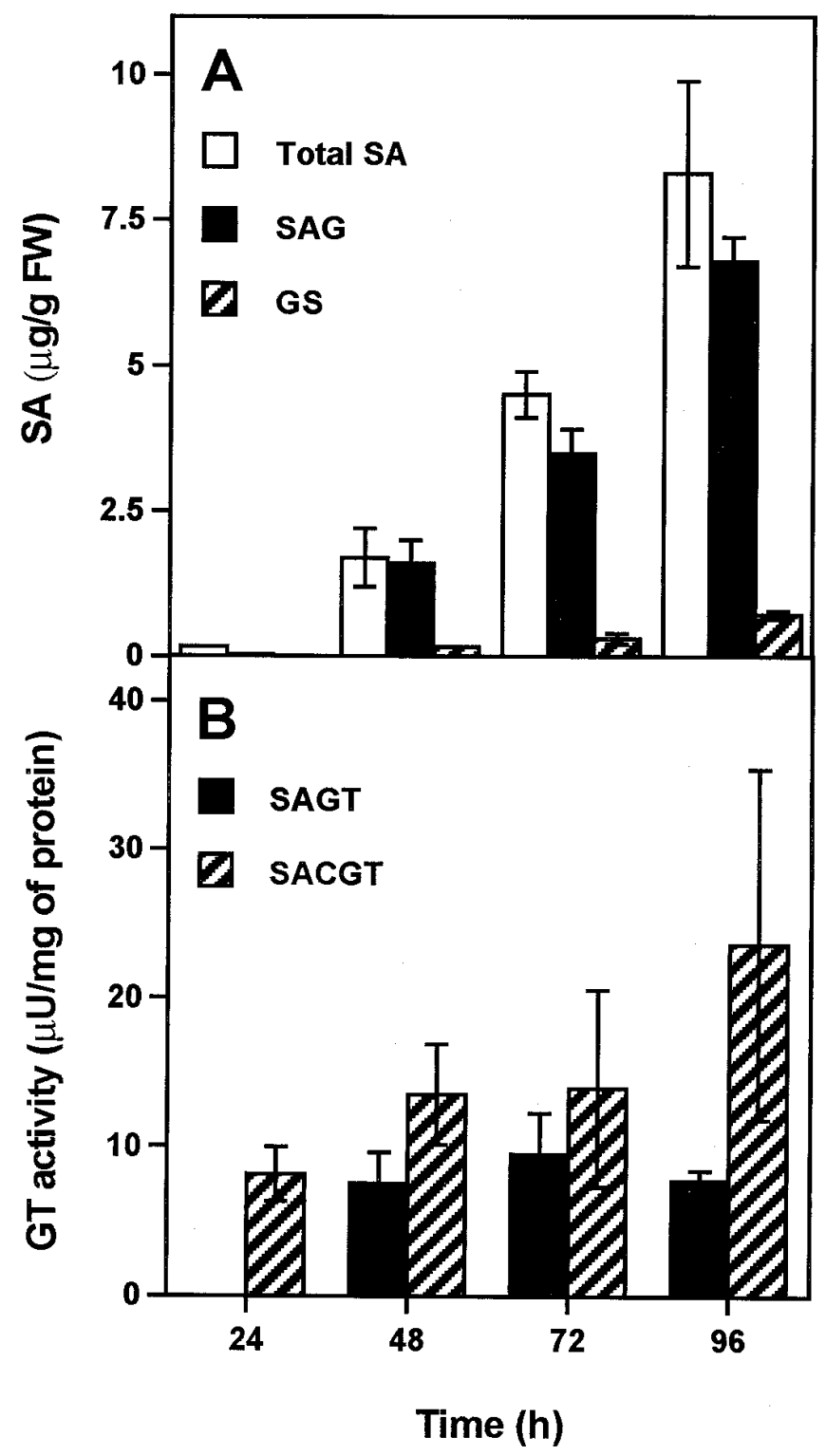

Fig. 2. Accumulation of salicylic acid 2-O- $\beta$-D-glucoside (SAG) and glucosyl salicylate (GS) in tobacco mosaic virus (TMV)-inoculated tobacco. Leaf samples were harvested at the indicated times. Samples were A, analyzed for SA content or $\mathbf{B}$, assayed for the activity of the enzymes catalyzing the formation of GS (SA carboxyl glucosyltransferase [SACGT]) and SAG (SA 2-O-glucosyltransferase [SAGT]). Values are means of three replicates $( \pm$ standard error) from different leaves after TMV inoculation. $\mathrm{FW}=$ fresh weight; $\mathrm{GT}=$ glucosyltransferase.
SA disappeared gradually and was no longer detectable at $24 \mathrm{~h}$ (Fig. 5). Two additional radioactive products appeared immediately after SA infiltration. Based on the enzyme hydrolysis pattern and retardation factor values of the two products, these compounds were identified as SAG and GS. Radioactive GS began to accumulate $1 \mathrm{~h}$ after SA infiltration, reached a maximal level by $6 \mathrm{~h}$, decreased, and eventually disappeared $\approx 48 \mathrm{~h}$ after SA infiltration. In contrast, radioactive SAG continued to accumulate for the duration of the experiment. More than $80 \%$ of $\left[{ }^{14} \mathrm{C}\right] \mathrm{SA}$ was present as SAG $24 \mathrm{~h}$ after infiltration.

Dose-dependent induction of two glucosyltransferase activities by SA. To establish dose-dependent induction of SACGT and SAGT, Xanthi-nc leaf disks were infiltrated with various nonphytotoxic concentrations of SA and incubated for $6 \mathrm{~h}$. In control tobacco leaves, which contained low levels of endogenous SA (100 $\mathrm{ng} \mathrm{g}^{-1}$ fresh weight), SAGT activity was not detectable, although low levels of SACGT activity were measured (Table 1).

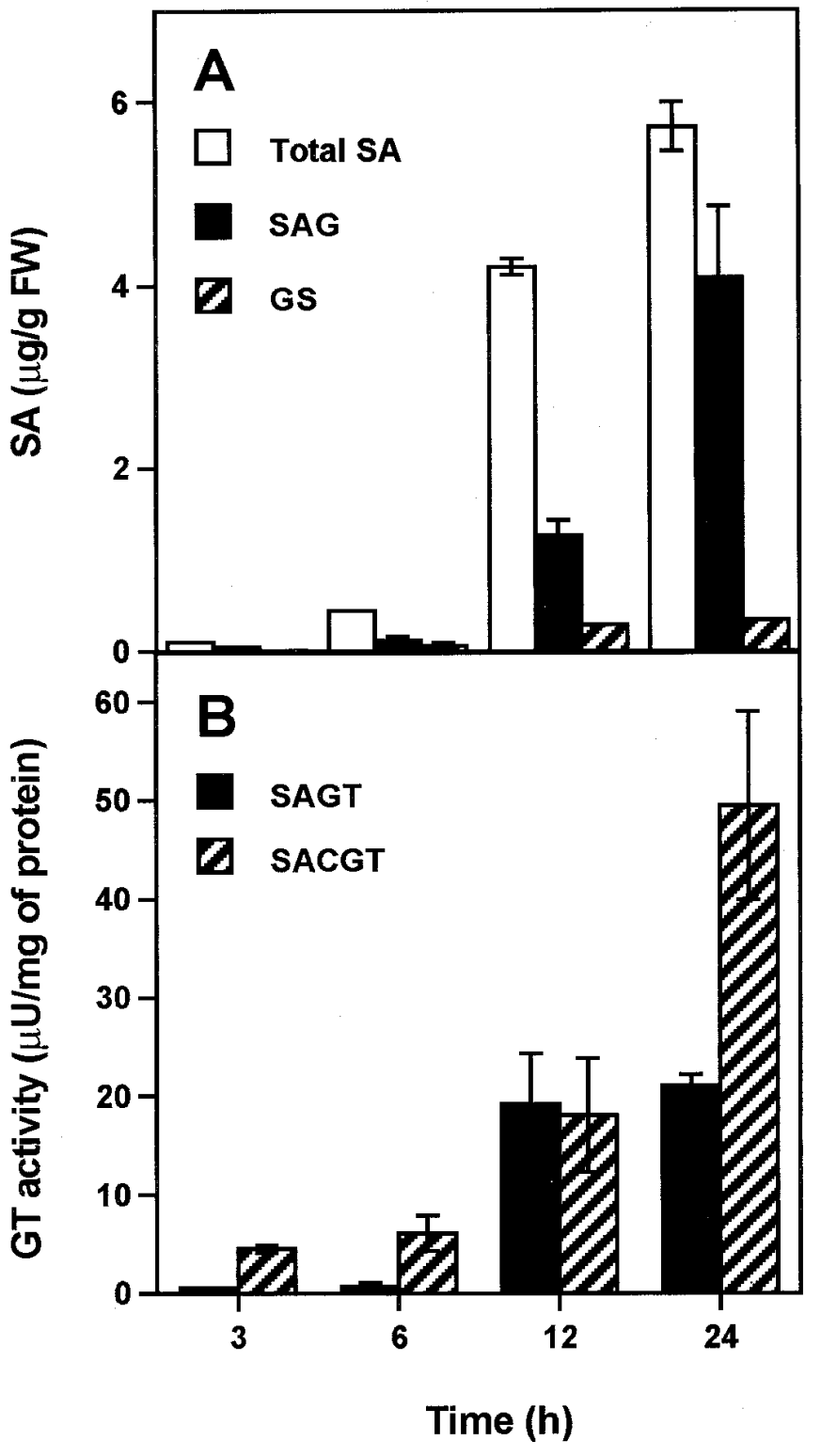

Fig. 3. Accumulation of salicylic acid (SA) conjugates in Pseudomonas syringae pv. phaseolicola-inoculated tobacco. Leaf samples were harvested at the indicated times. Samples were $\mathbf{A}$, analyzed for SA content or $\mathbf{B}$, assayed for the activity of two glucosyltransferases (GT): SA carboxyl glucosyltransferase (SACGT) and SA 2-O-glucosyltransferase (SAGT). Values are means of three replicates ( \pm standard error) from different leaves after inoculation with $P$. syringae pv. phaseolicola $. \mathrm{FW}=$ fresh weight; $\mathrm{SAG}=\mathrm{SA} 2-O-\beta-\mathrm{D}-$ glucoside; GS = glucosyl salicylate. 
As shown in previous experiments (Fig. 4B), both enzyme activities were inducible by exogenous SA. SAGT activity was 17-fold higher for the $1 \mathrm{mM}$ SA treatment than for the $10 \mu \mathrm{M}$ SA treatment, whereas SACGT activity increased 7-fold. When infiltrated with SA at concentrations between $100 \mu \mathrm{M}$ and $1 \mathrm{mM}$, both SA glucosyltransferase activities increased in a dose-dependent manner.

The structural similarity of GS and SAG (Fig. 1) suggests that the glucosylation of SA is catalyzed by the same enzyme or by similar enzymes. To determine whether two enzymes are present, and whether they have different molecular weights, a crude protein extract was applied to a gel filtration column. The in vitro enzyme activity of SACGT peaked in fractions two and three, whereas maximal SAGT activity was detected in fractions four and five (Fig. 6). In addition, two glucosyltransferase activities were found in different salt gradient fractions when protein samples were subjected to anion exchange chromatography (data not shown).

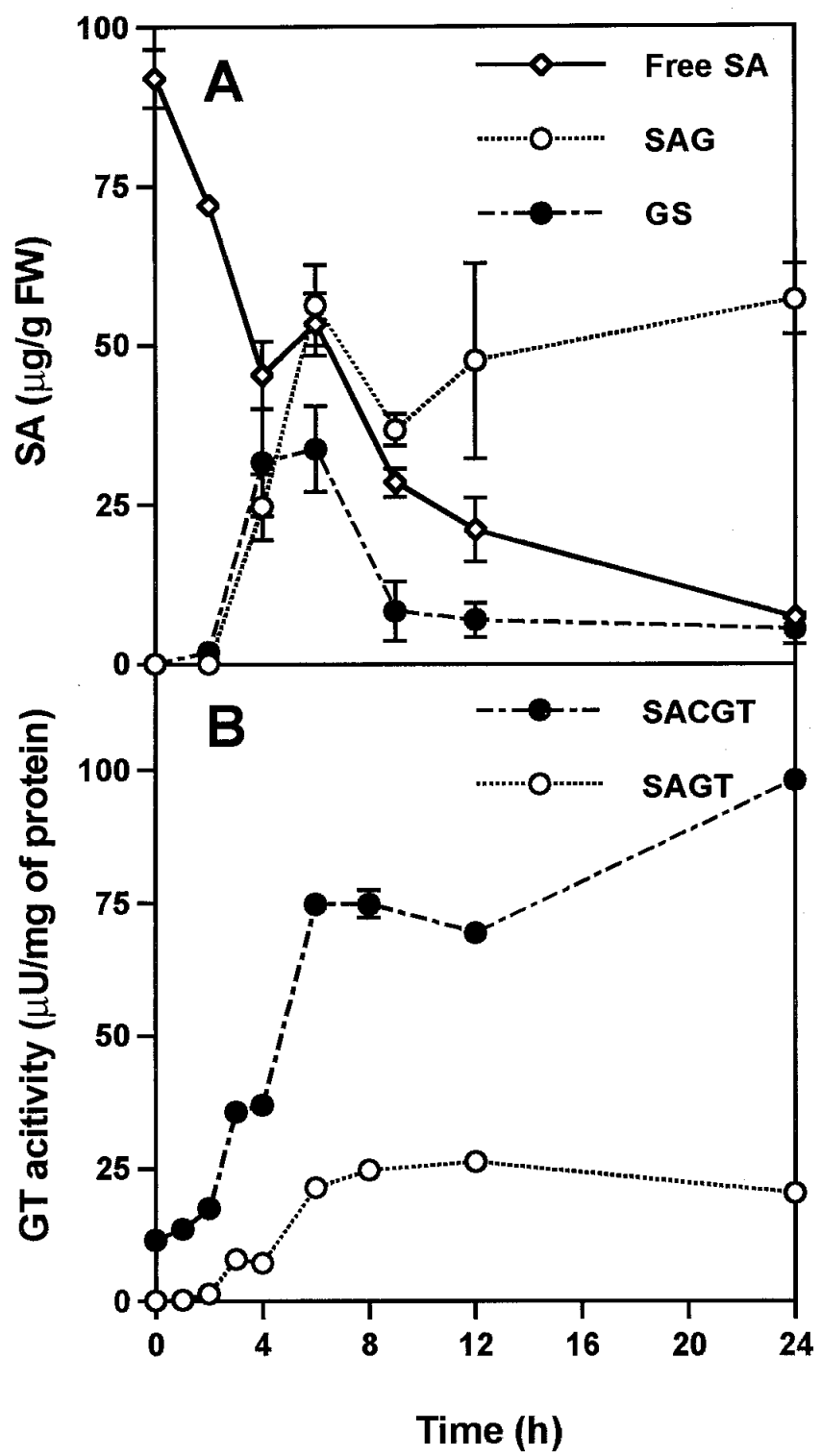

Fig. 4. Formation of salicylic acid 2-O- $\beta$-D-glucoside (SAG) and glucosyl salicylate (GS) in SA-infiltrated tobacco. Leaves were infiltrated with $1 \mathrm{mM}$ SA. Leaf samples were harvested at the indicated times after SA infiltration. Samples were A, analyzed for SA content or $\mathbf{B}$, assayed for the activity of the SA glucosylating enzymes: SA carboxyl glucosyltransferase (SACGT) and SA 2-O-glucosyltransferase (SAGT). Values are means of three replicates ( \pm standard error) from different leaves after SA infiltration. FW = fresh weight; GT = glucosyltransferase.

\section{DISCUSSION}

We identified GS as a relatively minor metabolite in tobacco plants inoculated with TMV or P. syringae pv. phaseolicola. The formation of this glucose ester in pathogen-inoculated tobacco was further supported by evidence showing parallel increases in the corresponding enzyme activity localized to the HR lesions. The temporal and spatial distribution of GS and its biosynthetic enzyme suggests that the induction of SACGT activity is required for synthesis of GS. We also confirmed earlier observations that SAG is a major metabolite in pathogen-inoculated plants. These results indicated that GS and SAG accumulated in a similar fash-

\section{Time (h)}

\section{$\begin{array}{lllllll}0 & 1 & 3 & 6 & 12 & 24 & 48\end{array}$}

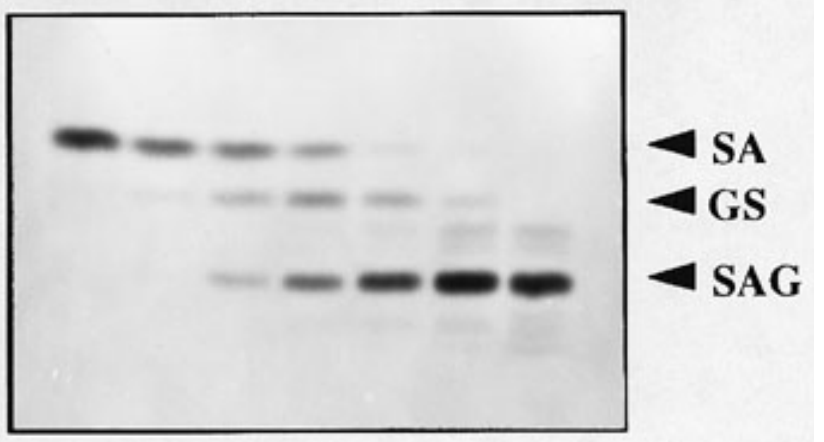

Fig. 5. Thin-layer chromatography (TLC) analysis of salicylic acid (SA) metabolites in $\left[{ }^{14} \mathrm{C}\right] \mathrm{SA}$-infiltrated tobacco. Samples were collected at the indicated times and analyzed on TLC plates by autoradiography and phosphorimager. GS = glucosyl salicylate; SAG = SA 2-O- $\beta$-D-glucoside .

TABLE 1. Induction of two salicylic acid (SA) glucosyltransferase enzyme activities by $\mathrm{SA}^{\mathrm{a}}$

\begin{tabular}{lccc}
\hline $\begin{array}{l}\text { SA } \\
(\mathrm{mM})\end{array}$ & $\begin{array}{c}\text { SA recovered }^{\mathrm{b}} \\
(\mu \mathrm{g} / \mathrm{g} \text { fresh weight })\end{array}$ & $\begin{array}{c}\text { SAGT }^{\mathrm{c}} \text { activity } \\
(\mu \mathrm{U} / \mathrm{mg} \text { protein })\end{array}$ & $\begin{array}{c}\text { SACGT }^{\mathrm{d}} \text { activity } \\
(\mu \mathrm{U} / \mathrm{mg} \text { protein })\end{array}$ \\
\hline 0 & $0.1 \pm 0.01$ & $\mathrm{ND}^{\mathrm{e}}$ & 11.6 \\
0.01 & $4.5 \pm 0.7$ & 6.6 & 28.2 \\
0.1 & $16.0 \pm 0.9$ & 22.4 & 31.2 \\
0.5 & $103.2 \pm 17.5$ & 55.4 & 91.8 \\
1 & $188.5 \pm 13.8$ & 101.5 & 183.5 \\
\hline
\end{tabular}

${ }^{a}$ Tobacco leaf disks were infiltrated with various concentrations of SA and incubated for $6 \mathrm{~h}$.

b Values are means ( \pm standard error) of triplicates for SA quantification and means of duplicates for enzyme activity.

${ }^{c}$ SA 2-O-glucosyltransferase.

d SA carboxyl glucosyltransferase.

${ }^{\mathrm{e}}$ Enzyme activity was below the limits of detection.

\section{$\begin{array}{llllll}1 & 2 & 3 & 4 & 5 & 6\end{array}$}

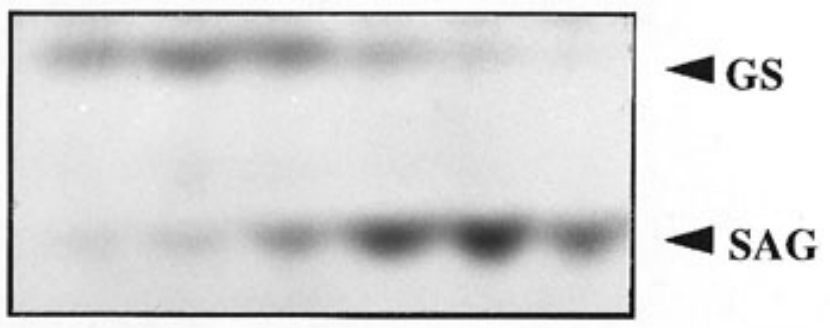

Fig. 6. Thin-layer chromatography (TLC) analysis of enzyme activities in six consecutive fractions of gel filtration chromatography. Soluble crude preparation was loaded on a Superose 12 gel filtration column. Fractions were eluted and assayed for enzyme activity as described in text. GS = glucosyl salicylate; SAG = salicylic acid 2-O- $\beta$-D-glucoside. 
ion in P. syringae pv. phaseolicola- and TMV-inoculated tobacco plants. Therefore, the formation of two glucosylated conjugates of $\mathrm{SA}$ is a naturally occurring phenomenon that follows the induction of SA biosynthesis in tobacco plants.

The radioactive SA feeding experiments showed that SA was initially metabolized to two glucosylated conjugates, GS and SAG, concomitant with the induction of the corresponding glucosyltransferases. We did not detect any other nonvolatile conjugated forms, such as amino acid conjugates, which have been reported in grapes and French beans $(4,31)$, or hydroxylated forms, which occur in many plants $(3,11,20)$. Therefore, if these conjugates exist in tobacco, they must occur as minor metabolites that were not detected by the methods described here.

Edwards (13) reported earlier that exogenously supplied SA was primarily glucosylated in SR 1 tobacco. This is consistent with our data, which showed that most of the endogenous (Figs. 2 and 3) and exogenous SA (Figs. 4 and 5) was converted to glucosylated forms when a different tobacco cultivar was used as a model system. Taken together, it seems likely that glucosylation of the carboxy and hydroxy groups are the primary reactions in the early metabolism of SA in tobacco.

The early appearance of GS (1 to $2 \mathrm{~h}$ after SA infiltration) in tobacco Xanthi-nc is distinct from the late formation of GS $(24 \mathrm{~h}$ after incubation with SA) observed in other tobacco cultivars $(N$. tabacum cv. Petit Havana SR 1) (13). This may reflect differences in the methods used to analyze both cultivars. Alternatively, the two cultivars may differ in their capacity to form GS. To distinguish between these possibilities, tobacco Xanthi-nc leaf disks were incubated with SA under the same conditions used for tobacco SR 1. This experiment showed that GS was formed by $2 \mathrm{~h}$ after SA incubation and increased slightly until $36 \mathrm{~h}$, whereas SAG accumulated gradually throughout the incubation period (data not shown). Evidently, formation of GS in Xanthi-nc tobacco occurred much earlier than in SR 1 tobacco, suggesting the synthesis of the glucose ester is regulated differently in the two tobacco cultivars. These results also showed that the timing of GS formation was the same in SA-infiltrated (Fig. 4) and SA-incubated Xanthi-nc leaves. The steady increase in GS throughout the incubation period was probably due to the continuous uptake of SA from incubation media.

In vivo tracer experiments (Fig. 5) that showed the steady accumulation of SAG and the transient formation of GS suggest that GS may be less stable than SAG. This may be due to the unstable nature of the ester compound or to its high activity in other metabolic processes. However, because the decrease in GS coincided with the increase in SAG (Figs. 4 and 5), it is possible that GS is an intermediate in the formation of SAG. After rapid formation of GS in response to high concentrations of SA, this conjugate may be directly converted to SAG. Alternatively, GS may be deglucosylated to free SA (Fig. 1). The in vitro activity of SACGT remained high after SA infiltration, even though the increase in its product, GS, was only transient. In contrast, SAGT activity was correlated with the formation of its product, SAG (Fig. 4). The discrepancy between high SACGT activity and low production of GS could be due to limited quantities of either of the substrates (UDPG and SA) within the subcellular compartment in which GS was synthesized. It also is possible that the enzyme activity in vivo may be much lower than in vitro.

Little is known about the role of SA glucosylation in tobacco. The glucosylation of SA occurs primarily in the vicinity of the HR lesions and is rarely detected in systemically protected tissues $(15,17)$. The spatial distribution of SA glucosides suggests that glucosylation is not necessary for induction of resistance and PR proteins in tobacco. In addition, the absence of SA glucosides in phloem exudates makes them unlikely candidates for the longdistance signal for systemic acquired resistance (SAR). A possible function of the glucosylation of SA might be detoxification of SA and regulation of its levels. In fact, the early accumulation of GS suggests that its formation may protect tobacco plants from the phytotoxic effects of SA. The same mechanism also may operate in virus- or bacteria-infected tobacco plants in which high levels of SA accumulate. However, it is unlikely that GS is involved in the further catabolism of SA, because the esterification of aromatic acids is thought to prevent oxidative decarboxylation (2). In contrast, the formation of SAG could represent a route of SA catabolism, because of the preferential accumulation of SAG and the late appearance of other unidentified metabolites of SA (Fig. 5). Evolution of ${ }^{14} \mathrm{CO}_{2}$ in SR 1 tobacco fed radioactive SA (13) also supports the hypothesis of the further catabolism of SA. Accumulation of SAG suggests that this compound may function as a slow-release storage form of SA, which may maintain SAR over extended periods of time. Similar storage mechanisms have been established for other plant hormones, including cytokinins (6).

We have demonstrated that two distinct glucosyltransferases are active in tobacco. However, we do not know whether the two enzymes originate from the same or different genes. Recently, we purified and characterized SACGT (H. Lee and I. Raskin, unpublished data); purification of SAGT is still in progress. Further biochemical and molecular studies with these enzymes and their corresponding genes will help elucidate the origins of these two enzymes and provide a better understanding of the mechanism and role of SA glucosylation in plant-pathogen interactions.

\section{ACKNOWLEDGMENTS}

We thank D. Ribnicky and P. Day for critical reading of the manuscript.

\section{LITERATURE CITED}

1. Anderson, R. A., Hamilton-Kemp, T. R., Loughrin, J. H., Hughes, C. G., Hildebrand, D. F., and Sutton, T. G. 1988. Green leaf headspace volatile from Nicotiana tabacum lines of different trichome morphology. J. Agric. Food Chem. 36:295-299.

2. Barz, W., Schlepphorst, R., Wilhelm, P., Kratzl, K., and Tengler, E. 1978. Metabolism of benzoic acids and phenols in cell suspension cultures of soybean and mung bean. Z. Naturforsch. 33:363-367.

3. Billek, G., and Schmock, F. P. 1967. Zur Biosynthese der Gentisinsäure. Monatsh. Chem. 98:1651-1654.

4. Bourne, D. J., Barrow, K. D., and Milborrow, B. V. 1991. Salicyloylaspartate as an endogenous component in the leaves of Phaseolus vulgaris. Phytochemistry 30:4041-4044.

5. Bradford, M. M. 1976. A rapid and sensitive method for quantitation of microgram quantities of protein utilizing the principle of protein-dye binding. Anal. Biochem. 72:248-254.

6. Brzobohaty, B., Moore, I., Kristoffersen, P., Bako, L., Campos, N., Schell, J., and Palme, K. 1993. Release of active cytokinin by a $\beta$-glucosidase localized to the maize root meristem. Science 262:1051-1054.

7. Buttery, R. G., Flath, R. A., Mon, T. R., and Ling, L. C. 1986. Identification of germacrene D in walnut and fig leaf volatiles. J. Agric. Food Chem. 34:820-822.

8. Buttery, R. G., Kamm, J. A., and Ling, L. C. 1984. Volatile components of red clover leaves, flowers and seed pods: Possible insect attractants. J. Agric. Food Chem. 32:254-256.

9. Buttery, R. G., Ling, L. C., and Wellso, S. G. 1982. Oat leaf volatiles: Possible insect attractants. J. Agric. Food Chem. 30:791-792.

10. Cauthen, W. L., and Hester, W. H. 1989. Accidental ingestion of oil of wintergreen. J. Fam. Pract 29:680-681.

11. Chadha, K. C., and Brown, S. A. 1974. Biosynthesis of phenolic acids in tomato plants infected with Agrobacterium tumefaciens. Can. J. Bot. 52: 2041-2046.

12. Delaney, T. P., Friedrich, L., and Ryals, J. 1995. Arabidopsis signal transduction mutant defective in chemically and biologically induced disease resistance. Proc. Natl. Acad. USA 92:6602-6606.

13. Edwards, R. 1994. Conjugation and metabolism of salicylic acid in tobacco. J. Plant Physiol. 143:609-614.

14. Enyedi, A. J., and Raskin, I. 1993. Induction of UDP-glucose:salicylic acid glucosyltransferase activity in tobacco mosaic virus-inoculated tobacco (Nicotiana tabacum) leaves. Plant Physiol. 101:1375-1380.

15. Enyedi, A. J., Yapani, N., Silvermann, P., and Raskin, I. 1992. Localization, conjugation and function of salicylic acid in tobacco during the hypersensitive reaction to tobacco mosaic virus. Proc. Natl. Acad. Sci. USA 89:2480-2484. 
16. Hammond-Kosack, K. E., Silverman, P., Raskin, I., and Jones, J. D. G. 1996. Race specific elicitors of Cladosporium fulvum induce changes in cell morphology and the synthesis of ethylene and salicylic acid in tomato plants carrying the corresponding $C f$ disease resistance gene. Plant Physiol. 110:1381-1394.

17. Hennig, J., Malamy, J., Grynkiewicz, G., Indulski, J., and Klessig, D. F. 1993. Interconversion of the salicylic acid signal and its glucoside in tobacco. Plant J. 4:593-600.

18. Herrmann, K. 1989. Occurrence and content of hydroxycinnamic acid compounds in foods. CRC Crit. Rev. Food Sci. Nutr. 28:315-345.

19. Herrmann, K. 1990. Salicylsaure und andere verbratete hydroxybenzoesauren und deren naturlich vorkommende verbindungen in lebensmitte. Ernahrungs-Umschau 37:108-112.

20. Ibrahim, R. K., and Towers, G. H. N. 1959. Conversion of salicylic acid to gentisic acid and $o$-pyrocatechuic acid, all labelled with carbon-14, in plants. Nature (Lond.) 184:1803.

21. Klämbt, H. D. 1962. Conversion in plants of benzoic acid to salicylic acid and its - $\beta$ - $d$-glucoside. Nature (Lond.) 196:491.

22. Klick, S., and Herrmann, K. 1988. Glucosides and glucose esters of hydroxybenzoic acids in plants. J. Chromatogr. 441:335-345.

23. Klick, S., and Herrmann, K. 1988. Analysis of naturally occurring hydroxybenzoic acid glucosides and hydroxybenzoyl glucoses and their behavior on a polyamide column. Z. Lebensm.-Unters. -Forsch. 187:444-450.

24. Lindgren, P. B., Peet, R. C., and Panopoulus, N. J. 1986. Gene cluster of Pseudomonas syringae pv. "phaseolicola" controls pathogenicity of bean plants and hypersensitivity on nonhost plants. J. Bacteriol. 168:512-522.

25. Malamy, J., Carr, J. P., Klessig, D. F., and Raskin, I. 1990. Salicylic acid: A likely endogenous signal in the resistance response of tobacco to tobacco mosaic virus. Science 250:1002-1004.

26. Malamy, J., Hennig, J., and Klessig, D. F. 1992. Temperature-dependent induction of salicylic acid and its conjugates during the resistance re- sponse to tobacco mosaic virus infection. Plant Cell 4:359-366.

27. Métraux, J.-P., Signer, H., Ryals, J., Ward, E., Wyss-Benz, M., Gaudin, J., Raschdorf, K., Schmid, E., Blum, W., and Inverardi, B. 1990. Increase in salicylic acid at the onset of systemic acquired resistance in cucumber. Science 250:1004-1006.

28. Raskin, I., Ehmann, A., Melander, W. R., and Meeuse, B. J. D. 1987. Salicylic acid: A natural inducer of heat production in Arum lilies. Science 237:1545-1556.

29. Schulz, M., Schnabl, H., Manthe, B., Schweihofen, B., and Casser, I. 1993. Uptake and detoxification of salicylic acid by Vicia faba and Fagopyrum esculentum. Phytochemistry 33:291-294.

30. Shulaev, V., Silverman, P., and Raskin, I. 1997. Airborne signaling by methyl salicylate in plant pathogen resistance. Nature (Lond.) 385:718-721.

31. Steffan, H., Ziegler, A., and Rapp, A. 1988. $N$-Salicyloyl-asparaginsaure: Eineneue phenolicsche verbindung aus reben. Vitis 27:79-86.

32. Tanaka, S., Hayakawa, K., Umetani, Y., and Tabata, M. 1990. Glucosylation of isomeric hydroxybenzoic acids by cell suspension cultures of Mallotus japonicus. Phytochemistry 29:1555-1558.

33. Umetani, Y., Kodakari, E., Yamamura, T., Tanaka, S., and Tabata, M. 1990. Glucosylation of isomeric hydroxybenzoic acids by cell suspension cultures of Mallotus japonicus. Phytochemistry 29:325-327.

34. Yalpani, N., Balke, N. E., and Schulz, M. 1992. Induction of UDP-glucose:salicylic acid glucosyltransferase in oat roots. Plant Physiol. 100: 1114-1119.

35. Yalpani, N., Schulz, M., Davis, M. P., and Balke, N. E. 1992. Partial purification and properties of an inducible uridine 5'-diphosphate-glucose: salicylic acid glucosyltransferase from oat roots. Plant Physiol. 100:457463.

36. Yalpani, N., Silverman, P., Wilson, T. M. A., Kleier, D. A., and Raskin, I. 1991. Salicylic acid is systemic signal and an inducer of pathogenesisrelated proteins in virus-infected tobacco. Plant Cell 3:809-818. 